\title{
Model tests on subsurface cavities below road pavement due to sand eruption from the liquefied ground
}

\section{J. Kuwano}

Saitama University, Saitama, Japan

R. Kuwano \& Y. Horiuchi

The University of Tokyo, Tokyo, Japan

ABSTRACT: A significant number of subsurface cavities was found in the liquefied ground after the 2011 Great East Japan earthquake. Using the results of the radar exploration conducted along the coastal area of Tokyo Bay, characteristics of subsurface cavities were investigated. The size and shape of the cavities are larger and thinner compared to those of cavities observed in the non-liquefied ground. A series of model tests was conducted in order to understand the mechanism of sand eruption and underground cavity formation when liquefaction occurs. It was found that the flow rate at the opening seems to be the most important factor for the sand eruption.

\section{INTRODUCTION}

The occurrence of sand liquefaction due to earthquakes is often identified by the erupted boiled sand on the ground surface. A trace of sand boiling is one of the most important evidences of the presence of liquefied layer. However, the erupted sand often causes trouble after the earthquake such as delay in the road restoration, generation and scattering of dust, and etc. Although liquefaction phenomena have been investigated in detail, sand boiling and eruption are not well understood.
Damage of roads was widely found in Tokyo Bay area, which suffered from damage by liquefaction, after the 2011 Great East Japan Earthquake with $\mathrm{M}=9.0$. Ground penetration radar exploration from a specially equipped car running at the maximum speed of $60 \mathrm{~km} / \mathrm{h}$ was carried out in Urayasu City, Shinkiba area and Narashino City for the total distance of $355 \mathrm{~km} .709$ hidden subsurface cavities were found by the radar and their characteristics were investigated (Sera et al. 2014, Kuwano et al. 2015). Locations of liquefaction subsurface cavities found by the investigation are shown in Figure 1 (Kuwano et al 2015).

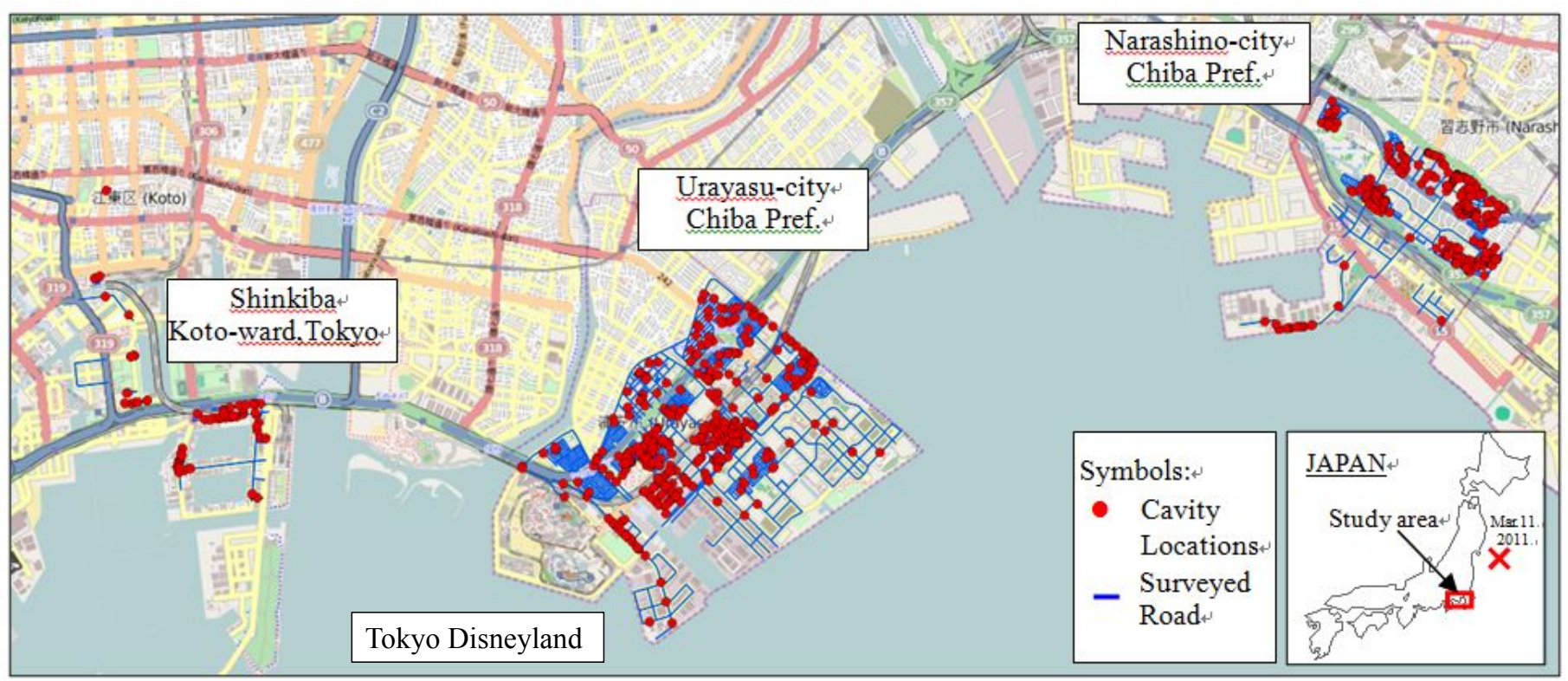

Figure 1. Locations of subsurface cavities caused by ground liquefaction (Kuwano et al. 2015). 
Table 1. Summary of subsurface cavity investigation.

\begin{tabular}{|l|l|l|l|}
\hline \multicolumn{2}{|c|}{} & $\begin{array}{l}\text { Ordinary } \\
\text { cavities }\end{array}$ & $\begin{array}{l}\text { Liquefaction } \\
\text { cavities }\end{array}$ \\
\hline \multicolumn{2}{|c|}{ Occurrence ratio } & $0.22 \mathrm{cav} . / \mathrm{km}$ & $1.56 \mathrm{cav} . / \mathrm{km}$ \\
\hline \multirow{3}{*}{ Average } & Area & $1.68 \mathrm{~m}^{2}$ & $2.38 \mathrm{~m}^{2}$ \\
\cline { 2 - 4 } & Thickness & $0.20 \mathrm{~m}$ & $0.13 \mathrm{~m}$ \\
\cline { 2 - 4 } & $\begin{array}{l}\text { Depth of cavity } \\
\text { ceiling }\end{array}$ & $0.38 \mathrm{~m}$ & $0.37 \mathrm{~m}$ \\
\hline
\end{tabular}
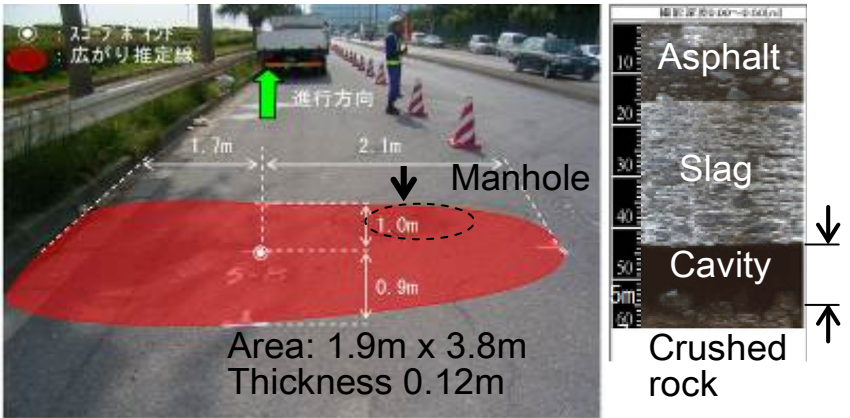

(a) Subsurface cavity around manhole.
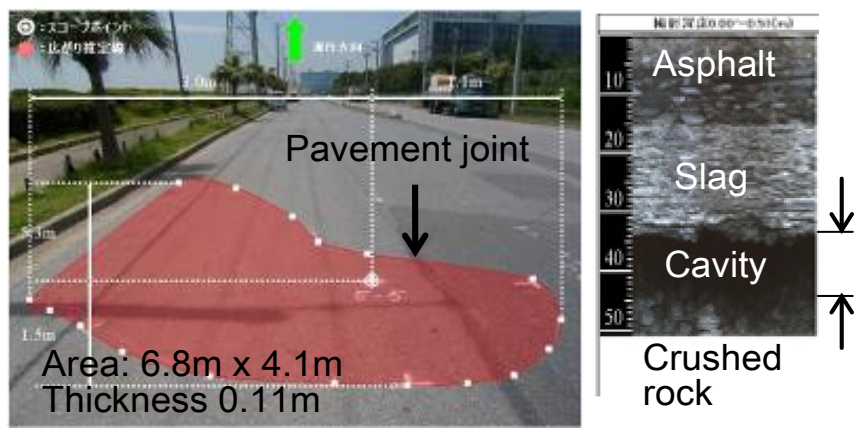

(b) Subsurface cavity near pavement joint

Figure 2. Examples of liquefaction cavities.

Cavities under roads are not always caused by ground liquefaction. Cavities in ordinary conditions are caused by other factors such as breakage of sewer pipes. Subsurface cavities of this type are formed when soil particles or sub-base materials are washed away into the pipe. A cavity thus formed from a certain depth of the ground expands with time, and when the strength of the pavement is not enough, a sudden cave-in finally occurs. Table 1 compares features of ordinary cavities and liquefaction cavities found in Tokyo Bay area. It is seen that the cavity occurrence ratio in liquefied areas is 7 times larger than that in the ordinary condition. Many of these cavities were thin, large in area occasionally more than $10 \mathrm{~m}^{2}$, and made by erosion at the road subbase leaving undulation at the cavity bottom according to the borehole camera pictures as shown in Figure 2 for example. Locations where many cavities were found coincided with large scale sand boiling, subsidence or cave-in of the road surface. The cavities were formed especially along pavement joints and around manholes, where there were gaps of pavement, and around buried sewer line structures.
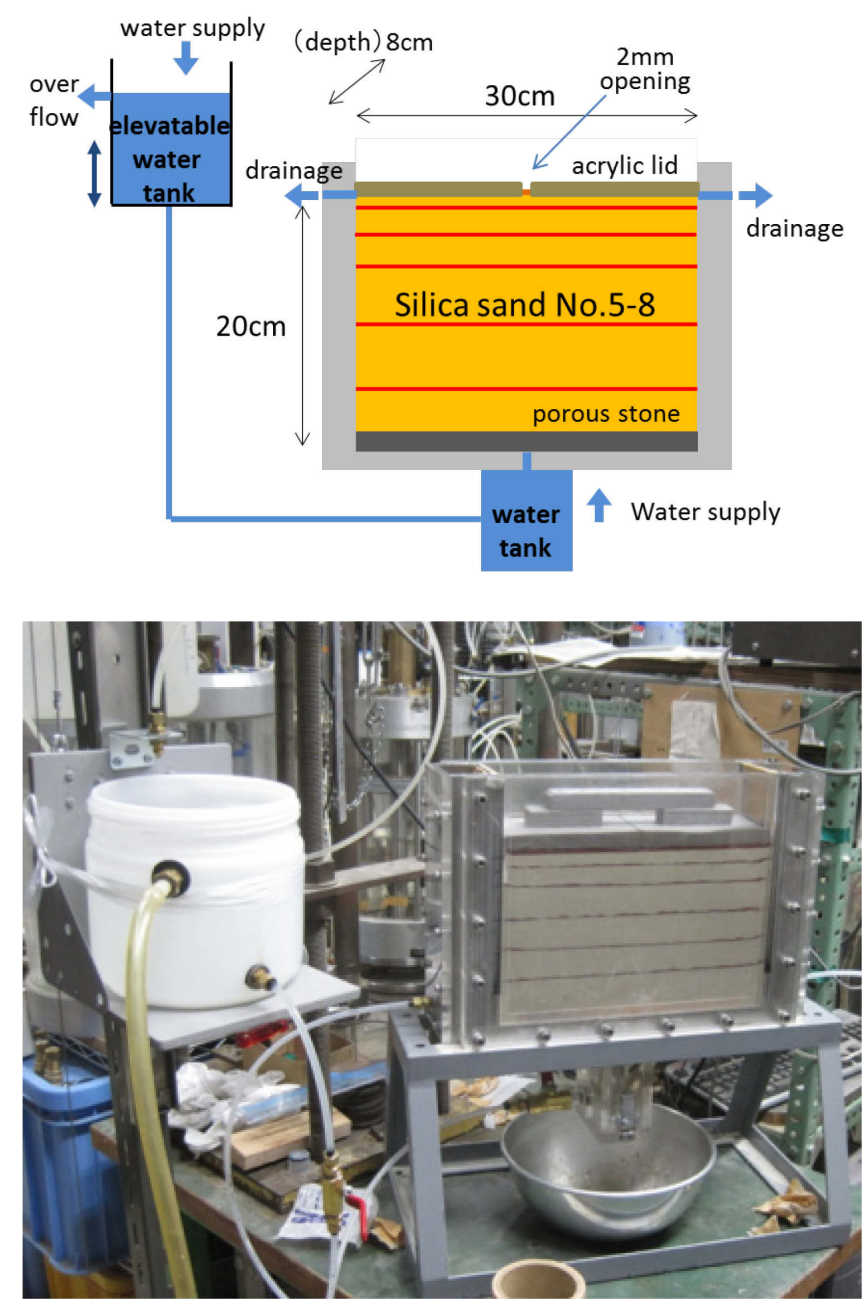

Figure 3. Photo and schematic figure of apparatus.

In this study, a series of model tests was carried out in order to understand the mechanism of sand eruption from the liquefied ground through the opening of pavement and the formation of the cavity beneath the pavement caused by liquefaction.

\section{TEST OUTLINE}

In order to investigate how the sand grains are transported from the liquefied layer, a series of laboratory model tests was conducted.

\subsection{Aapparatus}

A model ground was prepared in a soil chamber of $30 \mathrm{~cm}$ long, $8 \mathrm{~cm}$ wide and $20 \mathrm{~cm}$ high, as shown in Figure 3. Water was supplied from the bottom of the model ground. Hydraulic gradient of the water supply could be adjusted by the elevatable water tank connected to the bottom of the soil chamber. In order to simulate the boundary of relatively impermeable layer, e.g. asphalt pavement, surface of the model ground was covered by an acrylic lid having $2 \mathrm{~mm}$ wide opening in the center, from which boiling sand 
could be erupted. Water table was adjusted by the drainage at the side wall of the chamber.

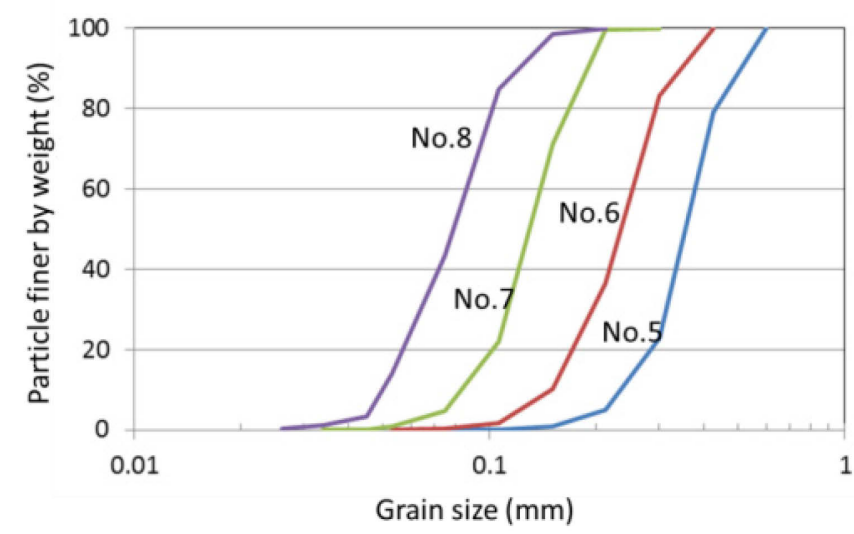

Figure 4. Particle size distribution of tested materials.
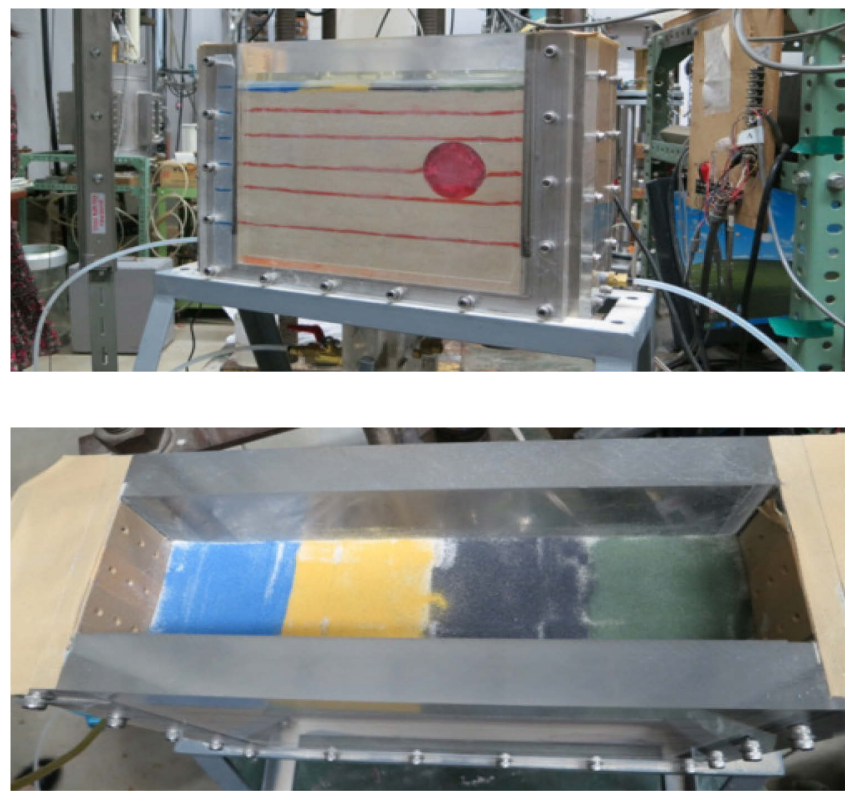

Figure 5. Example of the model ground setup.

\subsection{Model ground}

Silica sands No.5, 6, 7 and 8 were used for the material of the model ground. They have mean diameters of $0.36,0.23,0.13$ and $0.08 \mathrm{~mm}$ respectively. The particle size distributions of the used materials are shown in Figure 4. For silica sand No.7, maximum and minimum void ratios are 1.24 and 0.74 . Loose sand ground, relative density of approximately $50 \%$, was prepared by the air-pluviation. Colored sand was put on the surface and in front of the ground, as shown in Figure 5, for the observation of sand grains' movement.

\subsection{Test procedure}

Water was slowly supplied to the model ground from the bottom and the model ground was saturated in advance. Then the water tank was elevated at 50 $\mathrm{mm}$ intervals up to $1000 \mathrm{~mm}$ to apply additional hydraulic gradient to generate liquefaction in the ground. Sand grains lost effective stresses and upward steady seepage flow caused sand eruption from the opening in the lid. Three tests were conducted by applying vibration to generate liquefaction instead of applying upward seepage flow. The soil chamber was put on the shaking table and sinusoidal wave of $20 \mathrm{~Hz}$ with the maximum amplitude of $300 \mathrm{gal}$ was applied for 30 seconds. This vibration was repeated four times. In the case of static liquefaction by the upward seepage flow, a flow rate at the opening of the lid was obtained from the amount of drained water through it. In the case of dynamic liquefaction by the vibration, however, a flow rate at the opening of the lid was estimated from the settlement rate of the lid, which was monitored throughout the test, since the amount of drained water could not be measured during the vibration. The amount of settlement times the surface area was assumed to be the same as the amount of drained water through the opening. Test cases and the conditions were presented in Table 2.

Table 2. Test condition.

\begin{tabular}{lllll}
\hline & & \multicolumn{3}{c}{$\begin{array}{l}\text { Conditions when the sand eruption } \\
\text { began }\end{array}$} \\
\cline { 5 - 6 } Case & Silica & $\mathrm{D}_{50}$ & $\begin{array}{l}\text { Head difference } \\
(\mathrm{mm})\end{array}$ & $\begin{array}{l}\text { Flow rate at the } \\
\text { opening }(\mathrm{mm} / \mathrm{s})\end{array}$ \\
No. & sand & $(\mathrm{mm})$ & 37.50 \\
\hline 5w1 & No. 5 & 0.36 & 550 & 9.56 \\
6w1 & No. 6 & 0.23 & 400 & 8.00 \\
7w1 & No. 7 & 0.13 & 200 & 3.55 \\
8w1 & No. 8 & 0.08 & 250 & 19.45 \\
7v1 & No. 7 & 0.13 & 0 (vibration)* & 7.50 \\
8v1 & No. 8 & 0.08 & 0 (vibration)* & 5.55 \\
8v2 & No. 8 & 0.08 & 0 (vibration)* & 5 \\
\hline
\end{tabular}

*Sinusoidal wave with the amplitude of $300 \mathrm{gal}$.

\section{TEST RESULTS AND DISCUSSION}

\subsection{Sand eruption and boiling due to upward steady seepage flow}

Sand eruption was observed in all the test cases when the model ground was covered with the lid. The water head difference at the beginning of sand eruption is shown in Table 2. Although the drain lines were located at or below the model ground surface, the drainage could not keep up with the supply of water. Therefore the water table at the beginning of sand eruption came to be above the ground surface. When the water head difference became larger, the sand eruption started. The flow rate of water at the opening was measured and presented in Table 2.

At the beginning of sand eruption, it was observed that sand grains moved horizontally toward the opening in the gap between the lid and the model ground surface. Then, they were brought up through 
the opening and erupted as shown in Figure 6. Further increasing hydraulic gradient caused vertical movement of sand grains and a large amount of boiled sand flowed up from the opening. The ground under the opening seemed to be highly disturbed as shown in Figure 7. When the lid was not put on the model ground in the preliminary test, the whole ground heaved up, and finally significant sand boiling occurred at the center of the ground as shown in Figure 8.
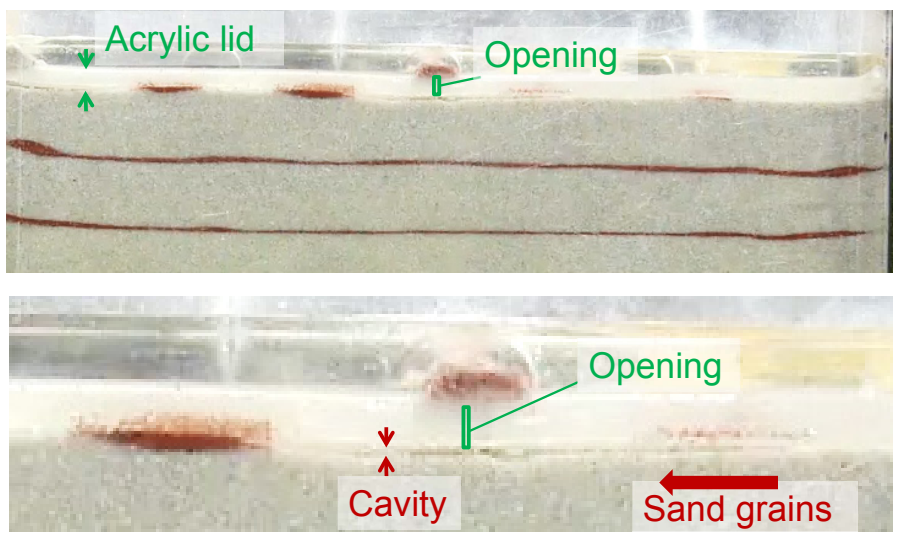

Figure 6. Movement of sand grains at the early stage of eruption. (Case 7w1)

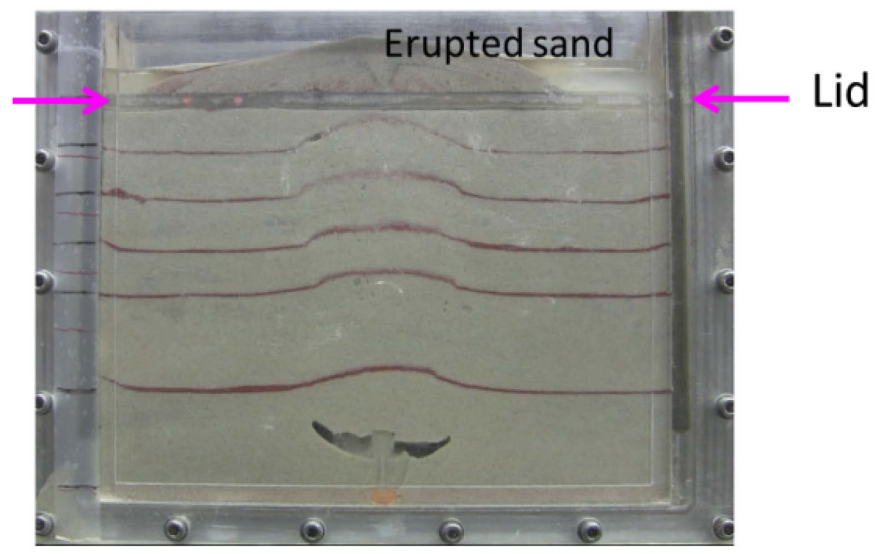

Figure 7. Deformation of the ground after large amount of sand eruption. (Case $7 \mathrm{w} 1, \Delta \mathrm{h}=1000 \mathrm{~mm}$ )

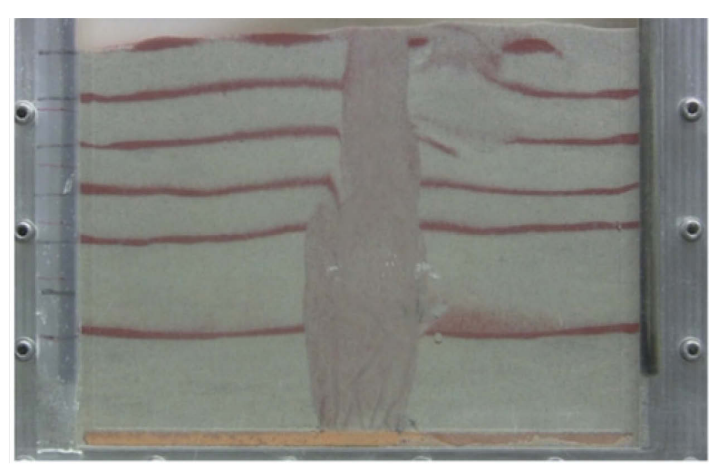

Figure 8. Movement of sand grains at the sand boiling. (Case 7w0, $\Delta \mathrm{h}=700 \mathrm{~mm}$ )

\subsection{Sand eruption from the liquefied layer due to vibration}

The sinusoidal wave of $20 \mathrm{~Hz}$ with the maximum acceleration of 300 gal was applied to the model ground for about 30 seconds. Soon after the vibration has started, the model ground was liquefied and started to settle as the shaking progressed. Sand eruption through the opening was only observed when the lid can move down following the settlement of liquefied ground. The movement of sand grains was mainly observed to be horizontal as shown in Figure 9 and Figure 10. Even after the multiple shaking, the large scale sand boiling did not occur.

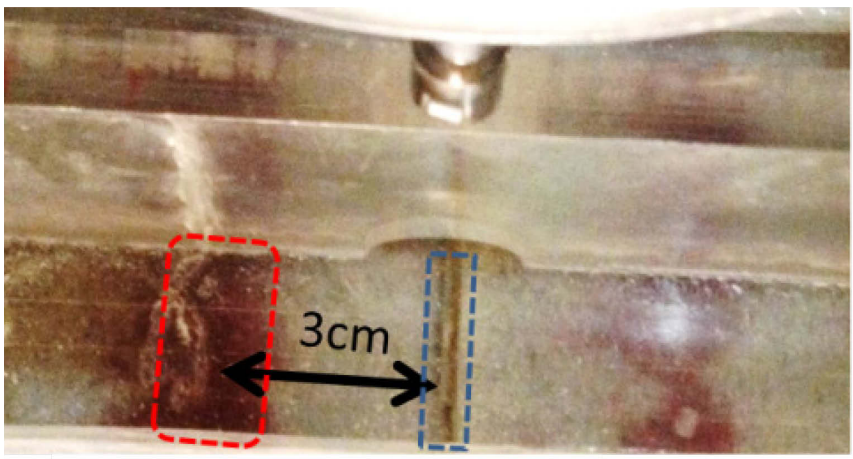

\section{Colored sand opening}

\section{Before shaking}

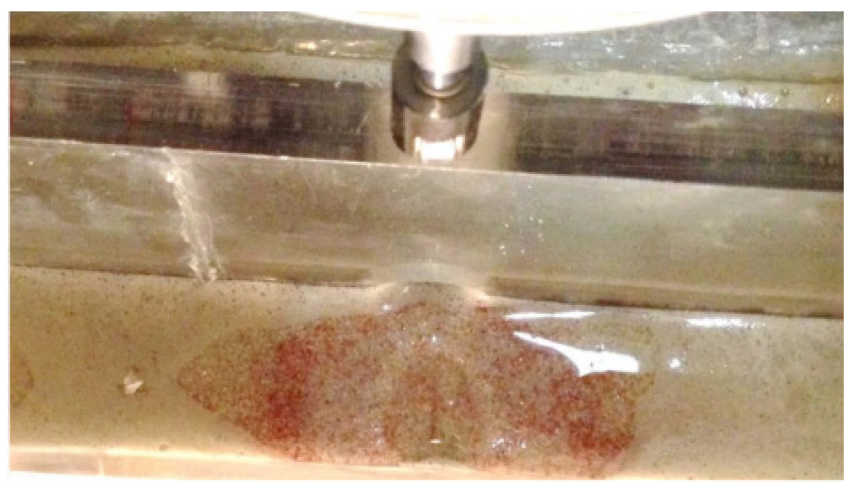

\section{After $1^{\text {st }}$ shaking}

Figure 9. Movement of sand grains on the ground surface in a shaking table test. (Case 7v1) 

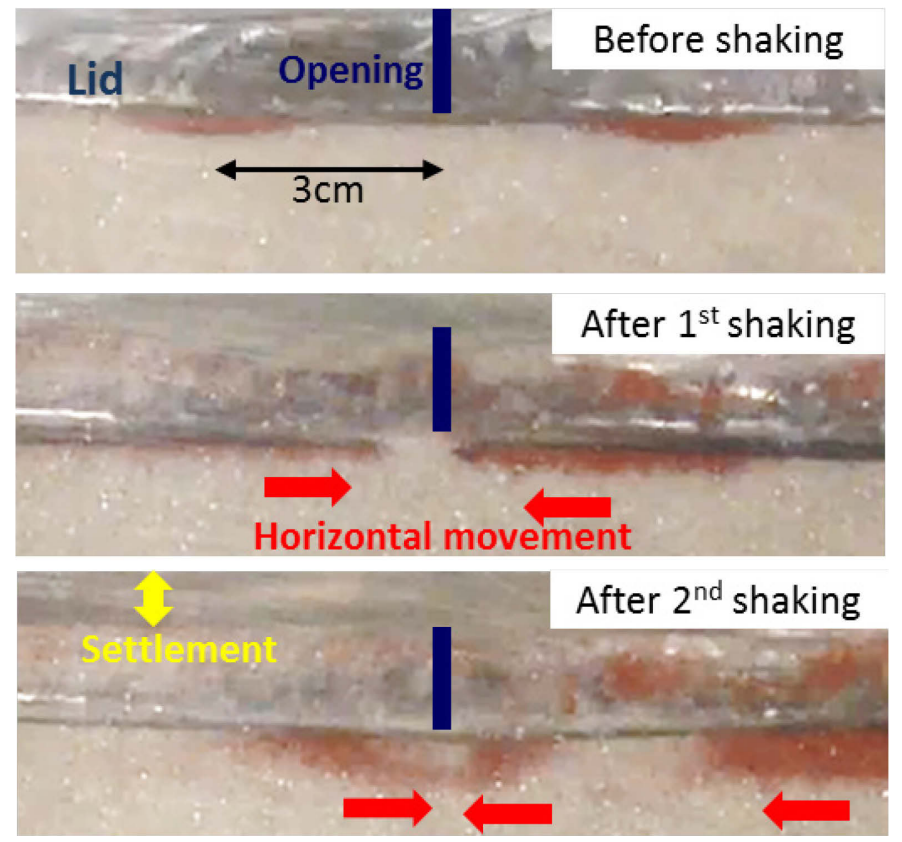

Figure 10. Movement of sand grains in the vertical plane near the opening observed in a shaking table test. (Case 7v1)

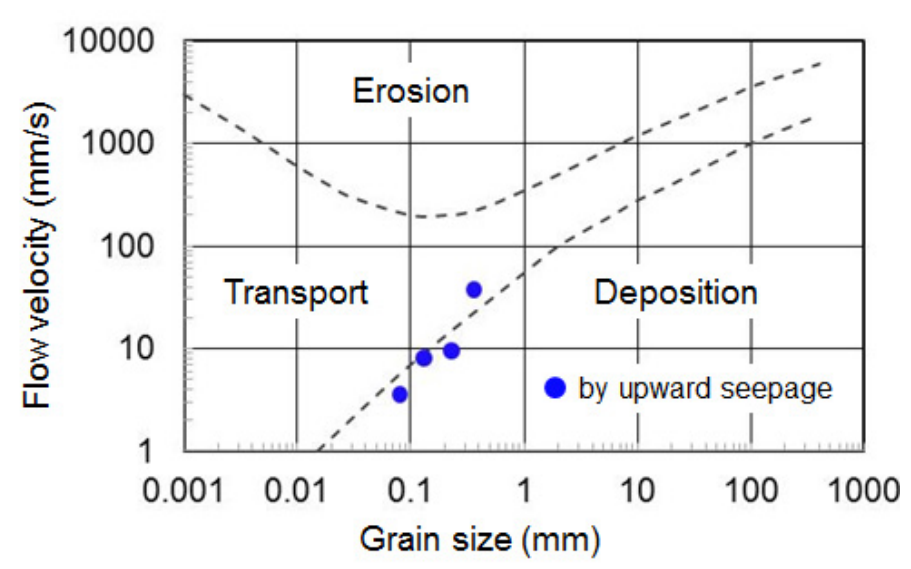

Figure 11. Flow velocity at the opening when the sand eruption started by steady upward seepage.

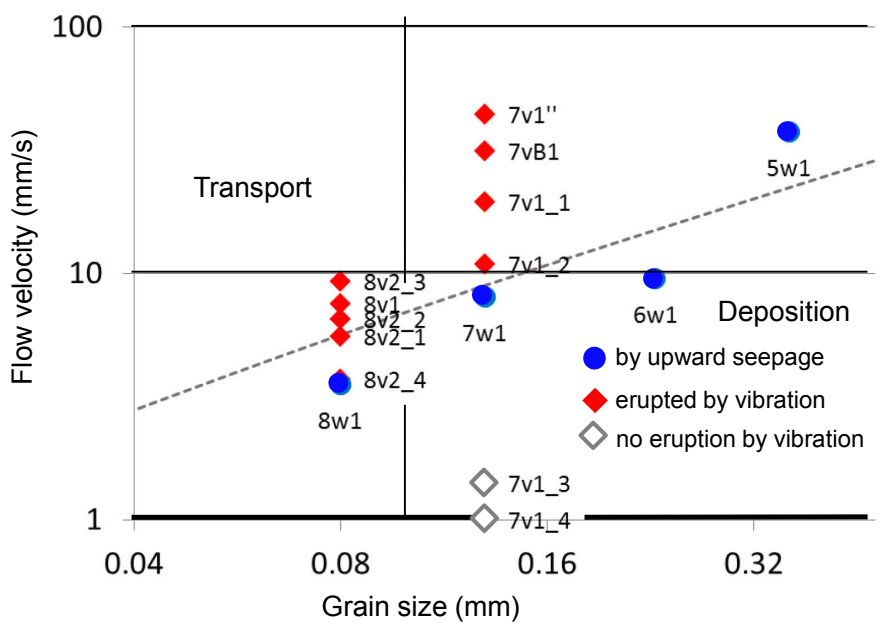

Figure 12. Flow velocity at the opening to cause sand eruption by upward seepage and vibration.

\subsection{Transportation of sand grains}

The flow rate at the opening to cause sand eruption was obtained by measuring the amount of drained water per unit time. They are shown in Table 2 . Pidwirny (2006) and Yee (2012) introduced Hjulström-Sundborg Diagram (Wikipedia, 2015) which originally proposed to determine whether a river will erode, transport, or deposit sediment as the boundaries in the diagram of flow velocity and grain size as shown in Figure 11. Measured flow rates to cause eruption of four sands with different grain sizes are also plotted in Figure 11 for the Cases $5 \mathrm{w} 1$ to $8 \mathrm{w} 1$, i.e. sand eruption due to upward seepage flow. It is seen that the data are located around the boundary between "Transport" and "Deposition". Flow rate at the opening should be high enough to bring out sand grains from the liquefied layer through an opening of the surface impermeable layer such as asphalt pavement and fine soil layer to cause sand eruption on the ground surface.

Three tests were conducted by applying vibration to generate liquefaction instead of applying upward seepage flow. In each test, vibration was repeated four times and designated as 8v1_n, where $\mathrm{n}$ indicates $\mathrm{n}^{\text {th }}$ application of the vibration of sinusoidal wave of $20 \mathrm{~Hz}$ with the maximum amplitude of $300 \mathrm{gal}$ for 30 seconds. In the case of vibration test, a flow rate at the opening of the lid was a resulting value caused by the ground vibration and could not be controlled, though a flow velocity to cause the initial sand eruption could be found in the case of upward seepage flow test by increasing head difference gradually. Flow velocities at the opening measured in the vibration tests are plotted in Figure 12, which is an enlarged view of Figure 11. A flow velocity causing sand eruption is plotted in red, whereas the velocity not causing sand eruption is plotted in gray. As seen in Figure 12, all the red dots showing sand eruption are on or above the boundary between "Transport" and "Deposition" in the HjulströmSundborg Diagram, whereas the gray dots of no sand eruption are below the boundary.

It was found that the flow rate at the opening seems to be the most important factors for the sand eruption. For the transportation of larger grains, higher flow velocities are required. When relatively impermeable soil layer covers liquefied soil, and if there are narrow openings in the impermeable layer, it is assumed that water flow concentrates on the cracks and the flow rate would be high. Sand particles can be transported up along the openings and reach the ground surface. 


\section{CONCLUSIONS}

A series of model tests was conducted to simulate sand eruption and subsurface cavity in the liquefied ground. Following conclusions were drawn from the study.

The cavity occurrence ratio in liquefied areas was 7 times larger than that in the ordinary condition. Many of these cavities were thin, large in area, and made by erosion at the road sub-base leaving undulation at the cavity bottom.

Horizontal movement of sand grains was observed in the early stage of sand boiling. When larger hydraulic gradient was applied, vertical movement of sand occurred.

Sand eruption occurred when the flow rate at the opening exceeded the threshold value of boundary between particle transportation and deposition in the case of sand eruption caused by the vibration as well as the upward steady seepage flow.

\section{REFRENCE}

Hjulström-Sundborg Diagram. 2015. https://en.wikipedia.org/ wiki/Hjulstr\%C3\%B6m_curve, Wikipedia, viewed on August 25, 2015.

Kuwano, J. and Kuwano, R. 2015. Mechanism of sand eruption from liquefied ground through gap of pavement and subsurface cavities, Proceedings of 15th Asian Regional Conference on Soil Mechanics and Geotechnical Engineering, Fukuoka, Japan, JPN-111.

Pidwirny, M. 2006. Erosion and Deposition. Fundamentals of Physical Geography, 2nd Edition. viewed on Sep 11, 2014, http://www.physicalgeography.net/fundamentals/10w.html, 2006.

Sera, R., Koike, Y., Nakamura, H., Kuwano, R. and Kuwano, J. 2014. Sub-surface cavities in the liquefied ground caused by the Great East Japan Earthquake, Geotechnical Engineering Journal, Japanese Geotechnical Society, 9(3), 323-339, (in Japanese).

Yee, T.W. 2012. Geosynthetics for erosion control in hydraulic environment, Proceedings of the 5th Asian Regional Conference on Geosynthetics (Geosynthetics Asia 2012), Bangkok, Thailand, 119-134.

\section{ACKNOWLEDGMENT}

The authors wish to thank Mr. Y. Koike and Ms. R. Sera, GEO SEARCH Co. Ltd., for providing the information of field investigation, and Mr. K. Ohnishi, former student of Saitama University, for his effort of laboratory tests. 